\title{
Pseudotumor and repeated dislocation after total hip arthroplasty with ceramic-on-metal bearing: a case report
}

\author{
Yin-Qiao Du ${ }^{1 \#}$, Tao Luo ${ }^{2 \#}$, Jing-Yang Sun ${ }^{1}$, Hai-Yang $\mathrm{Ma}^{1}$, Ming $\mathrm{Ni}^{1}$, Yong-Gang Zhou $^{1}$ \\ ${ }^{1}$ Department of Orthopaedics, Chinese People's Liberation Army General Hospital, Beijing, China; ${ }^{2}$ Department of Orthopaedics, Zhaoqing City's \\ Traditional Chinese Medical Hospital, Zhaoqing, China \\ \#These authors contributed equally to this work. \\ Correspondence to: Ming Ni, MD, PhD; Yong-Gang Zhou MD, PhD. Department of Orthopaedics, Chinese People's Liberation Army General \\ Hospital, Beijing, China. Email: niming301@163.com; ygzhou301@163.com.
}

\begin{abstract}
Pseudotumor is a rare complication following total hip arthroplasty (THA) with ceramic-onmetal (CoM) bearings. There is still in controversy about the using of CoM bearings when conducting surgery. We reported a case of a 47-year-old woman who underwent cementless CoM bearing THA because of left Crowe type III dislocation of the hip (DDH) in December 2009. One year after THA, she presented at our hospital complaining of crunching noise, pain, and decreased level of function. A revision surgery was performed because of left hip instability in December 2010, we adjusted the excessive anteversion of stem and replaced the head by using the long-neck ceramic head. In February 2019, she was admitted to our hospital complaining of repeated dislocation and fracture of greater trochanter. During the rerevision surgery, a pseudotumor and grey synovial sac were revealed. The metal liner was replaced with a ceramic liner and the greater trochanter was reattached using the Cable-Ready system. Clinical outcome was successful at 6 months postoperatively. This case vividly demonstrated CoM bearing should be avoided in THA. The pseudotumor highly destructed the periprosthetic soft tissues and the bone, which leaded to dislocation and periprosthetic fracture. The surgeon should be aware of the complication so that prompt diagnosis and treatment can be performed.
\end{abstract}

Keywords: Total hip arthroplasty (THA); pseudotumor; ceramic-on-metal (CoM); dislocation; case report

Submitted Feb 24, 2020. Accepted for publication Jul 15, 2020.

doi: 10.21037/apm-20-478

View this article at: http://dx.doi.org/10.21037/apm-20-478

\section{Introduction}

Total hip arthroplasty (THA) is a common and successful treatment of patients suffering from development dislocation of the hip (DDH) that significantly reduces pain and improves function and quality of life $(1,2)$. And the search for the ideal bearing surface combination of THA that has minimal wear and permits durable long-term results is ongoing (3). Concern about the longevity of standard polyethylene leads to the increased use of hard-on-hard bearings, such as metal-on-metal (MoM). More recently, pseudotumor have been found in MoM bearing THA due to metal debris particles $(4,5)$. Pseudotumor was originally found in metal-on-polyethylene (MoP) bearing THA due to polyethylene wear particles and was used to describe solid granulomatous masses that leaded to extensive tissue necrosis (6). Daniel et al. defined pseudotumor as a spectrum of abnormal periprosthetic soft tissue reactions developed in relation to both MoM bearing and MoP bearing THA, which causes a granulomatous mass or destructive cystic lesions (6). These lesions are no-neoplastic lesion believe to worsen progressively and resulted in both bone and soft tissue extensive destruction (6). Clinically, pseudotumor may present in a number of ways, including pain, presence of a palpable lump and spontaneous instability/dislocation $(4,6)$. To address the adverse issues of metal debris particles and pseudotumor, other hard bearings were introduced such as ceramic-on-ceramic (CoC). However, early-generation 
$\mathrm{CoC}$ bearing hips were fraught with complications included squeaking and ceramic fracture. Therefore, the ceramic-onmetal $(\mathrm{CoM})$ bearing were recommended without the added risk of ceramic fracture, squeaking and the damaging effects of elevated metal ion levels (7). Some studies of CoM hip simulator analyses (8) and limited clinical results with shortterm follow-up (9) showed the wear rate of CoM bearing was significantly less than MoM bearing wear. Interestingly, there is a paucity of CoM cases involving pseudotumor and subsequent implant loosening reported in the literature (10). To our knowledge, there has been no previous report of pseudotumor and repeated dislocation in CoM bearing THA.

In the present report, this is first case report of pseudotumor and repeated dislocation after THA with CoM bearing in a patient with Crowe III DDH. We present the following article in accordance with the CARE reporting checklist (available at http://dx.doi.org/10.21037/ apm-20-478).

\section{Case presentation}

In December 2009, a 47-year-old woman with left Crowe type III DDH visited our hospital because of a chief complaint of pain 44 years after surgery of hip preservation. The patient did not have any specific personal or family history of disease. The patients underwent cementless CoM bearing THA in 2009 using $56 \mathrm{~mm}$ Pinnacle acetabular shell, cobalt-chromium (CoCr) metal liner, $36 \mathrm{~mm}$ Biolox delta ceramic femoral head, a S-ROM titanium alloy femoral stem $(16 \mathrm{~mm} \times 11 \mathrm{~mm} \times 150 \mathrm{~mm})$ with titanium sintered proximal cone (16 B) (DePuy, Warsaw, Indiana, USA). On the acetabular side the acetabular shell was positioned at the anatomical center of rotation of the hip with femoral head autograft and encirclage wring was done for lesser trochanter to prevent fractures.

In November 2010, she presented at our hospital complaining of crunching noise, pain and walking with two crutches after THA. X-ray radiographs revealed normal alignment and the position of the hip prothesis without no signs of loosening. The serum C-reactive protein (CRP), erythrocyte sedimentation rate and interleukin 6 were within normal limits. She was diagnosed with left hip instability according to examination. Then, the revision of the left hip was performed in December 2010. Considering the satisfied stability of the stem and acetabular shell, we adjusted the excessive anteversion of stem $\left(5^{\circ}\right)$ and replaced the head by using the long-neck ceramic head $(36+9 \mathrm{~mm})$ with retaining $\mathrm{CoCr}$ metal liner and the well-fixed stem and acetabular shell. After aggressive debridement and thorough lavage, the incision was closed.

The postoperative period was uneventful with substantial functional improvement. The patient was able to begin partial weight-bear with an assistive device within six weeks after revision THA. Six weeks after surgery, she gradually resumed full weight-bearing activities. During the followup period, the patient always complained of mild discomfort in the left hip. Six dislocations of the left hip had occurred between July 2012 and November 2017 and were treated by manual reduction at outside institutions.

In December 2017, she was hospitalized again for fracture of greater trochanter after an accidental fall on the left hip at outside institution. Fracture failed to heal two months after strict bed rest. After that, the patients could walk with two crutches. Three dislocations had again occurred between April 2018 and December 2018 and were treated by manual reduction at outside institutions.

In February 2019, she was admitted to our hospital complaining of repeated dislocation. Physical examination revealed an antalgic gait and painful decreased left hip range of motion. Examination of the left hip showed flexion of $70^{\circ}$, external rotation of $30^{\circ}$, and internal rotation of $10^{\circ}$. She did have a Trendelenburg sign. The surgical site was appropriately healed, and the overlying skin was benign. There was no palpable soft tissue mass. The patient's weight, height, and body mass index were $71 \mathrm{~kg}, 160 \mathrm{~cm}$, $27.7 \mathrm{~kg} / \mathrm{m}^{2}$, respectively.

$\mathrm{X}$-rays of the left hip demonstrated THA with hard-onhard bearing surface combination. There was no radiographic evidence of catastrophic hardware failure. There was fracture of greater trochanter and no loosening of acetabular shell. Acetabular inclination was $53^{\circ}$ and anteversion was $30^{\circ}$. The femoral stem appeared to be well fixed.

The patient was evaluated to rule out infection. The hip was aspirated preoperatively. The synovial red blood cell count was full visual field per high power field. And white blood cell count, polymorphonuclear \% and leukocyte esterase were normal. Bacterial cultures of the synovial fluid were negative for growth in the aspirate at 21 days for aerobic, anaerobic, and fungal species. Likewise, the serum CRP, erythrocyte sedimentation rate and interleukin 6 were normal.

She was diagnosed with repeated dislocation and fracture of greater trochanter (Vancouver A type). Re-revision left THA was performed. Intraoperatively, exploration of the capsule revealed a pseudotumor, surrounding grey synovial sac and a large amount of dark red fluid. The fluid was 

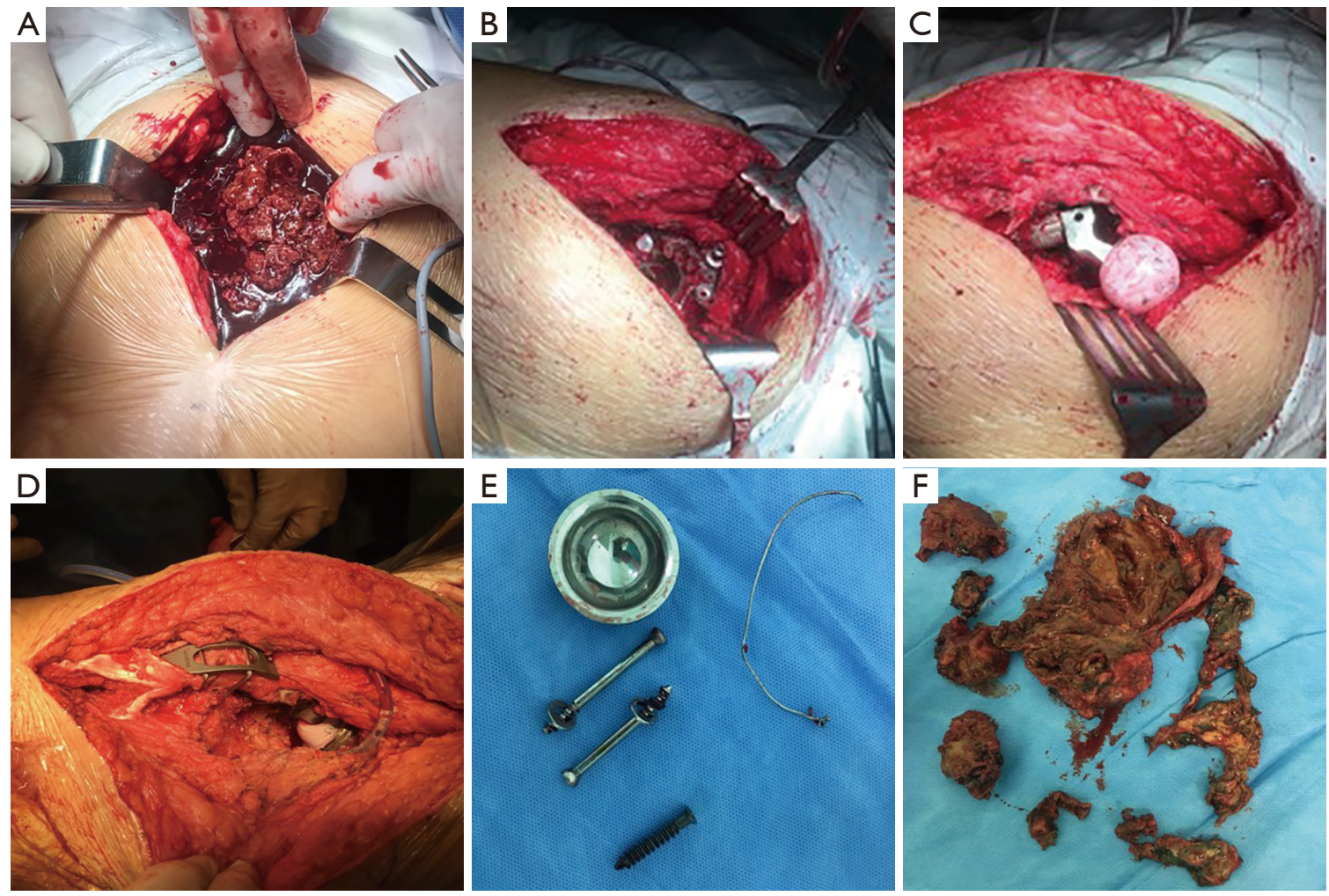

Figure 1 Intraoperative photographs of re-revision total hip arthroplasty. (A) Exploration of the capsule revealed a pseudotumor and a large amount of dark red fluid; (B) the dark grey soft tissue was observed around the acetabular shell; (C) metal contaminations on the surface of ceramic head; (D) Cable-Ready system was used to fix the greater trochanter; (E) explanted components; (F) explanted pseudotumor and inflammatory soft tissue.

aspirated and sent to bacterial cultures. The cystic soft tissue swelling extending to the hip joint. The dark grey soft tissue was observed around the acetabular shell. The pseudotumor and synovial sac around prothesis were then excised. The head autograft healed well and two screws for fixation were removed. The intraoperative frozen section of the excised mass revealed less than 5 polymorphonuclear leukocytes per high-power field in all the three specimens. The patient's left hip was easily dislocated. The proximal femoral cone, stem and acetabular shell were well-fixed on manual manipulation and the femoral head was solidly engaged onto the femoral neck. The surface of ceramic head had a large "black strip", which demonstrated metal contaminations. Gross inspection of the trunnion demonstrated no evidence of fretting or discoloration. The metal liner demonstrated no evidence of edge loading, backside wear, fretting or discoloration and it was noted to be appropriately engaged into the acetabular shell before explantation. The metal liner was replaced with a ceramic liner. The greater trochanter was reattached using the Cable-Ready system (Zimmer Biomet, Warsaw, Indiana, USA). The components were verified as being stable and extensive debridement was conducted before closing the wound (Figure 1).

Intraoperative bacterial cultures were negative for aerobic, anaerobic, and fungal species at 21 days. Histologic analysis of the synovial tissue of the left hip was notable for pigment-laden macrophages and the gray-brown particles (Figure 2).

The acute postoperative course was uneventful, and the patient began rehabilitation with two crutches on postoperative day 2. The patient had no postoperative complications and was discharged from the hospital on postoperative day 5. At 7 weeks postoperatively, she could ambulate without any assistive devices.

At the 6-month postoperative visit, the patient had no pain and recurrent dislocation in the left hip. The $\mathrm{X}$-ray at immediate and 6 months postoperatively showed 

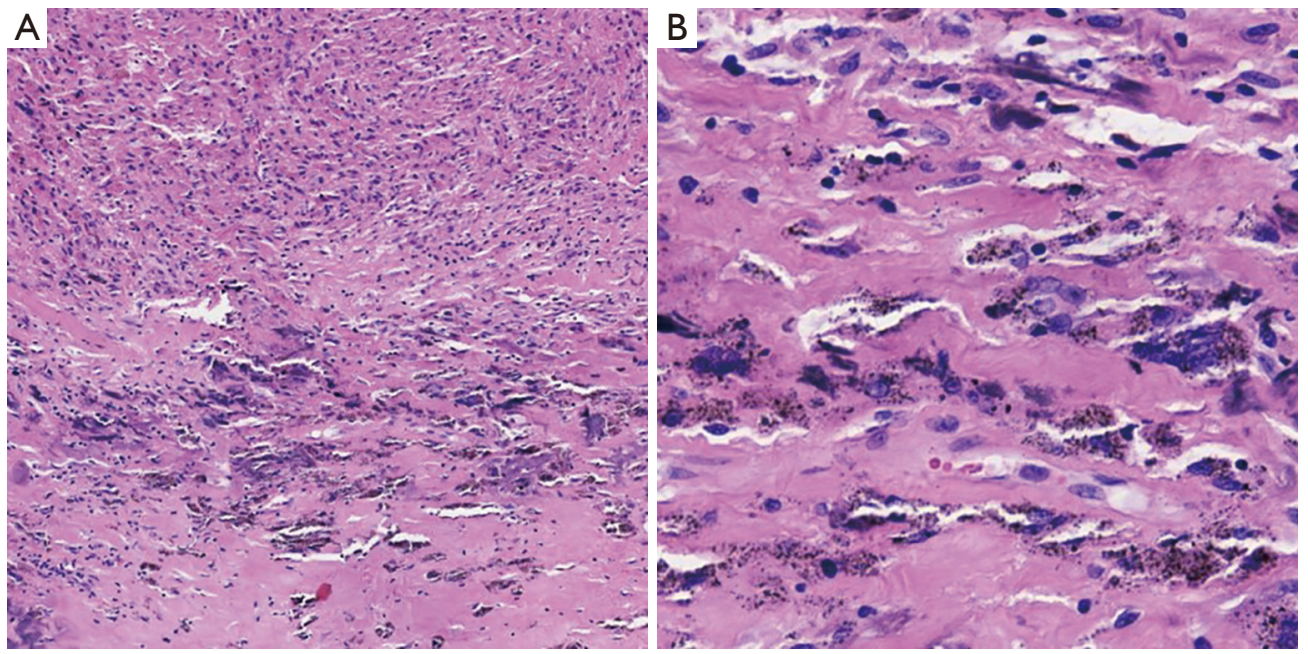

Figure 2 Histological section (hematoxylin and eosin stain). (A) Photomicrograph demonstrated lymphocytes, fibrosis, fibrin exudation, pigment-laden macrophages and metal particles $(\times 100)$; (B) magnification of the histiocytes contained the gray-brown metal particles in the tissue $(\times 400)$.

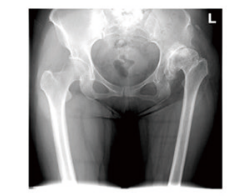

Preoperative X-ray

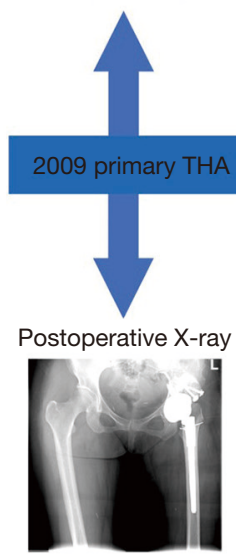

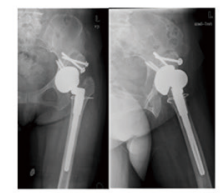

Preoperative X-ray
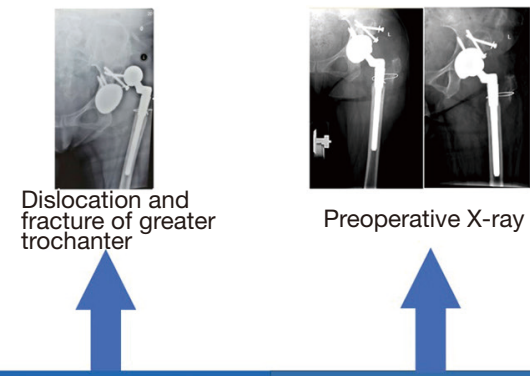

Preoperative X-ray
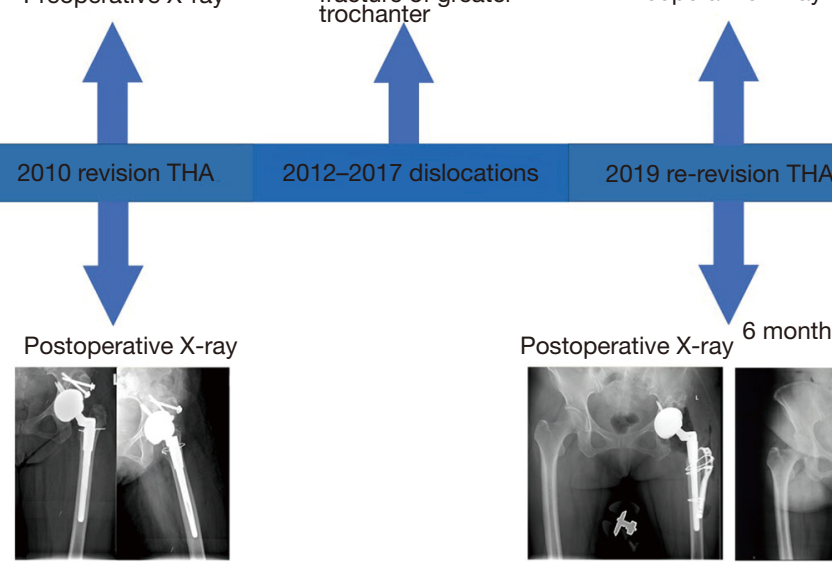

evision THA
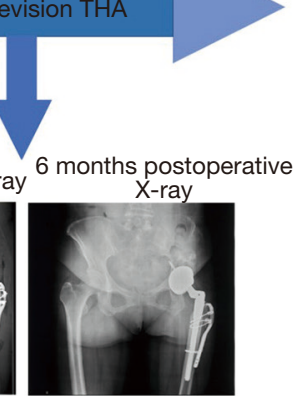

Figure 3 Timeline of patient's therapy. THA, total hip arthroplasty

unremarkable pseudotumor surrounding the hip and the hip was stability (Figure 3). The Harris hip score improved from 45 preoperatively to 87 postoperatively at 6 months.

All procedures performed in studies involving human participants were in accordance with the ethical standards of the institutional and/or national research committee(s) and with the Helsinki Declaration (as revised in 2013).
Written informed consent was obtained from the patients for publication of this manuscript and any accompanying images.

\section{Discussion}

Little was known about CoM bearing THA and their 
clinical outcome. Firkins et al. (7) in 2001 investigated the wear properties and debris morphology of a novel hardness CoM bearing prosthesis, in comparison with MoM bearing in a physiological anatomical hip joint simulator. They found that the wear rates of CoM bearing $\left(0.01 \mathrm{~mm}^{3} / 10^{6}\right.$ cycles) were approximately 100 -fold lower than that of MoM bearing $\left(1.23 \mathrm{~mm}^{3} / 10^{6}\right.$ cycles). The wear particles were $13.9 \mathrm{~nm}$ for $M o M$ bearing and $6.11 \mathrm{~nm}$ for CoM bearing after five million cycles. Other studies reported a similar outcome $(8,11)$. Williams et al. (11) also revealed the wear pattern appeared as beveling rim of $\mathrm{CoCr}$ metal liner and was much more pronounced in the CoM bearing compared with MoM bearing.

Reinders et al. (12) in a simulator study revealed that although the CoM exhibited mean wear results as good as those for $\mathrm{CoC}$, CoM bearing was a highly sensitive wear-couple and exhibited considerable variation in wear. In contrast, $\mathrm{CoC}$ bearing showed consistently low wear rates and greater reliability. Affatato et al. (13) did not recommend the using of hybrid specimens $(\mathrm{CoM})$, because of an increase in wear for the hybrid specimens with respect to that of $\mathrm{CoC}$ ones in an in-vitro hip simulator study. Zhu et al. (14) revealed the evidence for in vivo incompatibility between ceramic and metal counterparts through a spectroscopic study of two short-term retrieval cases of ceramic head belonging to CoM THA. They found that incorporation of metal ions into the ceramic lattices could be recognized as due to frictionally assisted phenomena occurring at the ceramic surface (14). The diffusion of metal ions induced lattice shrinkage in the zirconia phases and altered the mechanical equilibrium of the ceramic phases, which eventually disrupted the bearing surfaces and hindered the performance of CoM bearing THA (14). The present case also clearly demonstrated metal transfer on the ceramic head surface. During re-revision, we replaced the metal liner with a ceramic liner, which had consistently low wear rates and greater reliability.

However, limited clinical data of CoM bearing THA were available. Isaac et al. (15) reported the median increase in blood chromium and cobalt at 12 months after surgery was 0.08 and $0.22 \mu \mathrm{g} / \mathrm{L}$, respectively, in CoM bearing. Comparable values for MoM bearing were 0.48 and $0.32 \mu \mathrm{g} / \mathrm{L}$. Kazi et al. (16) in a study of 94 hips with CoM bearing found that mean whole blood levels of metal ions were significantly elevated compared with normal values at 2 years postoperatively. Maurer-Ertl et al. (17) showed the mean concentrations of $3.1 \mu \mathrm{g} / \mathrm{L}$ for cobalt and $1.6 \mu \mathrm{g} / \mathrm{L}$ for chromium, respectively, in $13 \mathrm{CoM}$ bearings at a mean
58 months follow-up. Chromosomal analysis demonstrated both structural and aneuploidy mutations and there was a significantly increased incidence of fractures and losses than in the normal population. Cadossi et al. (9) showed that the chromium and cobalt levels in CoM bearing THA were significantly higher at 3-year follow-up than before surgery. All the CoM bearing THA achieved excellent clinical results in the short-term follow-up, but the significance of high metal ion levels, diffusion of metal ions, chromosomal aberration and considerable variation in wear in the longterm remained concerns $(9,16)$. Interestingly, three case reports described pseudotumor formation and implants loosening after THA with CoM bearing $(3,18,19)$.

Pseudotumor formation in MoM bearing THA had reported this phenomenon frequently $(5,20)$. The Pseudotumor was associated with high levels of chromium and cobalt in large diameter and physical activity $\mathrm{MoM}$ bearing THA (20). The high levels of metal ions were associated with high wear rates, corrosion of taper and edge loading (6). Component malposition was likely to be another factor in the formation of pseudotumor. In MoM bearing, an inclination of acetabular shell of more than $55^{\circ}$ and anteversion angel greater than $20^{\circ}$ were in related to an increased serum chromium and cobalt levels (21). Acetabular shell malposition leading to failure of CoM bearing THA was reported by Isaac et al. who found that a malpositioned acetabular shell with inclination more than $50^{\circ}$ and/or anteversion more than $25^{\circ}$ resulted in the significantly elevated $(>10 \mu \mathrm{g} / \mathrm{L})$ serum cobalt and chromium levels (15). However, studies by Schouten et al. (22) and Kazi et al. (16) failed to demonstrate the correlation. It is currently unknown if the patient's acetabular shell inclination $\left(53^{\circ}\right)$ in this case was responsible for the wear and subsequent pseudotumor formation. No evidence of edge loading was noted on gross inspection of the explanted metal liner.

Pseudotumor was associated not only with a soft-tissue mass and osseous changes of osteolysis and erosions but also with damage to the periprosthetic soft tissues, which leaded to soft-tissue and muscle necrosis, osseous denudation, pathological fractures and spontaneous dislocations (6). In this case, dislocations of the left hip repeatedly occurred since July 2012 and fracture of greater trochanter was occurred in December 2017. All the above complications were likely to be caused by the pseudotumor, which highly destructed the periprosthetic soft tissues and the bone. In the management of fracture of greater trochanter, the Cable-Ready system was used to fix the fracture.

The strengths of this case were the demonstration of the 
disadvantages of CoM bearing in THA. However, the first limitation of this case was that the blood chromium and cobalt after primary THA were not analyzed. And the ion concentration should be tested in the future. The second was the lack of preoperative MRI. And the MRI could further clarify the diagnosis.

In conclusion, pseudotumor was not a common complication after CoM bearing THA. The pseudotumor highly destructed the periprosthetic soft tissues and the bone, which leaded to dislocation and periprosthetic fracture. The surgeon should be aware of the complication so that prompt diagnosis and treatment can be performed.

\section{Acknowledgments}

Funding: This work was supported by National Key Research and Development Program of China (N.O.2017YFB1104104).

\section{Footnote}

Reporting Checklist: The authors have completed the CARE reporting checklist. Available at http://dx.doi.org/10.21037/ apm-20-478

Conflicts of Interest: All authors have completed the ICMJE uniform disclosure form (available at http://dx.doi. org/10.21037/apm-20-478). The authors have no conflicts of interest to declare.

Ethical Statement: The authors are accountable for all aspects of the work in ensuring that questions related to the accuracy or integrity of any part of the work are appropriately investigated and resolved. All procedures performed in studies involving human participants were in accordance with the ethical standards of the institutional and/or national research committee(s) and with the Helsinki Declaration (as revised in 2013). Written informed consent was obtained from the patients for publication of this manuscript and any accompanying images.

Open Access Statement: This is an Open Access article distributed in accordance with the Creative Commons Attribution-NonCommercial-NoDerivs 4.0 International License (CC BY-NC-ND 4.0), which permits the noncommercial replication and distribution of the article with the strict proviso that no changes or edits are made and the original work is properly cited (including links to both the formal publication through the relevant DOI and the license).
See: https://creativecommons.org/licenses/by-nc-nd/4.0/.

\section{References}

1. Du YQ, Sun JY, Ma HY, et al. Leg Length Balance in Total Hip Arthroplasty for Patients with Unilateral Crowe Type IV Developmental Dysplasia of the Hip. Orthop Surg 2020;12:749-55.

2. Shen J, Sun J, Ma H, et al. High Hip Center Technique in Total Hip Arthroplasty for Crowe Type II-III Developmental Dysplasia: Results of Midterm Follow-up. Orthop Surg 2020;12:1245-52.

3. Pulley BR, Trinh TQ, Bentley JC, et al. Adverse reaction to metal debris in a patient with acetabular shell loosening 8 years after ceramic-on-metal total hip arthroplasty. Arthroplast Today 2015;1:93-8.

4. Pandit H, Glyn-Jones S, McLardy-Smith P, et al. Pseudotumours associated with metal-on-metal hip resurfacings. J Bone Joint Surg Br 2008;90:847-51.

5. Crawford DA, Adams JB, Morris MJ, et al. Revision of Failed Metal-on-Metal Total Hip Arthroplasty: Midterm Outcomes of 203 Consecutive Cases. J Arthroplasty 2019;34:1755-60.

6. Daniel J, Holland J, Quigley L, et al. Pseudotumors associated with total hip arthroplasty. J Bone Joint Surg Am 2012;94:86-93.

7. Firkins PJ, Tipper JL, Ingham E, et al. A novel low wearing differential hardness, ceramic-on-metal hip joint prosthesis. J Biomech 2001;34:1291-8.

8. Williams S, Al-Hajjar M, Isaac GH, et al. Comparison of ceramic-on-metal and metal-on-metal hip prostheses under adverse conditions. J Biomed Mater Res B Appl Biomater 2013;101:770-5.

9. Cadossi M, Mazzotti A, Baldini N, et al. New couplings, old problems: Is there a role for ceramic-on-metal hip arthroplasty? J Biomed Mater Res B Appl Biomater 2016;104:204-9.

10. Naik LG, Shon WY, Clarke IC, et al. Pseudotumor and Subsequent Implant Loosening as a Complication of Revision Total Hip Arthroplasty with Ceramic-on-Metal Bearing: A Case Report. Hip Pelvis 2018;30:276-81.

11. Williams S, Schepers A, Isaac G, et al. The 2007 Otto Aufranc Award. Ceramic-on-metal hip arthroplasties: a comparative in vitro and in vivo study. Clin Orthop Relat Res 2007;465:23-32.

12. Reinders J, Sonntag R, Heisel C, et al. Wear performance of ceramic-on-metal hip bearings. PLoS One $2013 ; 8: \mathrm{e} 73252$. 
13. Affatato S, Spinelli M, Squarzoni S, et al. Mixing and matching in ceramic-on-metal hip arthroplasty: an in-vitro hip simulator study. J Biomech 2009;42:2439-46.

14. Zhu W, Pezzotti G, Boffelli M, et al. Chemistry-driven structural alterations in short-term retrieved ceramic-onmetal hip implants: Evidence for in vivo incompatibility between ceramic and metal counterparts. J Biomed Mater Res B Appl Biomater 2017;105:1469-80.

15. Isaac GH, Brockett C, Breckon A, et al. Ceramic-on-metal bearings in total hip replacement: whole blood metal ion levels and analysis of retrieved components. J Bone Joint Surg Br 2009;91:1134-41.

16. Kazi HA, Perera JR, Gillott E, et al. A prospective study of a ceramic-on-metal bearing in total hip arthroplasty. Clinical results, metal ion levels and chromosome analysis at two years. Bone Joint J 2013;95-B:1040-4.

17. Maurer-Ertl W, Pranckh-Matzke D, Friesenbichler J, et al. Clinical Results and Serum Metal Ion Concentrations following Ceramic-on-Metal Total Hip Arthroplasty at a Mean Follow-Up of 60 Months. Biomed Res Int 2017;2017:3726029.

Cite this article as: Du YQ, Luo T, Sun JY, Ma HY, Ni M, Zhou YG. Pseudotumor and repeated dislocation after total hip arthroplasty with ceramic-on-metal bearing: a case report. Ann Palliat Med 2021;10(5):5818-5824. doi: 10.21037/apm-20-478
18. Lakhotia D, Kumar P. Pseudotumour Complicated by Implant Loosening One Year After revision Ceramic on Metal Total Hip Arthroplasty: A Case Report. J Orthop Case Rep 2017;7:82-6.

19. Deshmukh AJ, Rathod PA, Rodgers WH, et al. Early Failure of a Ceramic-on-Metal Total Hip Arthroplasty: A Case Report. JBJS Case Connect 2012;2:e25.

20. Hjorth MH, Mechlenburg I, Soballe K, et al. Physical Activity Is Associated With the Level of Chromium but Not With Changes in Pseudotumor Size in Patients With Metal-on-Metal Hip Arthroplasty. J Arthroplasty 2018;33:2932-9.

21. De Haan R, Pattyn C, Gill HS, et al. Correlation between inclination of the acetabular component and metal ion levels in metal-on-metal hip resurfacing replacement. J Bone Joint Surg Br 2008;90:1291-7.

22. Schouten R, Malone AA, Tiffen C, et al. A prospective, randomised controlled trial comparing ceramic-onmetal and metal-on-metal bearing surfaces in total hip replacement. J Bone Joint Surg Br 2012;94:1462-7. 